\title{
THE THEORETICAL AND EXPERIMENTAL WETTING OF POLYCAPROLACTONE NANOFIBRE LAYERS BY GELATIN HYDROGEL
}

\author{
Radek JIRKOVEC, Pavel HOLEC, Tomas KALOUS, Jiri CHVOJKA \\ Department of Nonwovens and Nanofibrous Materials, Faculty of Textile Engineering, Technical University of \\ Liberec, Czech Republic, EU, radek.jirkovec@tul.cz
}

https://doi.org/10.37904/nanocon.2021.4351

\begin{abstract}
The study is focused on the wetting of nanofibrous layers of polycaprolactone. In the study, we proceeded to compare layers from direct current spinning and alternating current spinning. During the study, it was found that direct current spinning produces hydrophilic layers, and alternating current spinning produces hydrophobic layers. The study also found that the contact angle is affected by the solvent system. Due to the widespread use of polycaprolactone in tissue engineering, wetting of the fibrous layers with a gelatin hydrogel was also performed in the experiment. During the study, the Kwok-Neumann and Li-Neumann models were used to calculate the surface energy of the fibrous layers, and these models were also used to calculate the theoretical contact angles that the gelatin hydrogel will make on the fibrous layers. The study showed that the used models could predict how the fibre layers will be wetted with the prepared hydrogel.
\end{abstract}

Keywords: Nanofibres, polycaprolactone, gelatin, electrospinning, hydrogel, wetting

\section{INTRODUCTION}

Cell adhesion to a material is affected by many different influences, one of them is the wettability of the material. [1] Wetting is the ability of a liquid to spread over a solid surface. [2] One of the basic parameters describing the wetting of the material is the value of the contact angle that the selected liquid makes on the given material. The value of the contact angle describes the shape of the applied drop, its value as well as the shape of the drop, however, depends on the surface tension of the given liquid, on the free surface energy of the solid and on the interfacial energy between the liquid and the solid. The relationship between these quantities is described using Young's equation (1). [3]

$\gamma_{s v}-\gamma_{s l}=\gamma_{l v} * \cos \theta$

Where:

$$
\begin{aligned}
& \theta \text { - contact angle } \\
& \gamma_{l v} \text { - surface tension of the liquid } \\
& \gamma_{s v} \text { - surface energy of the solid } \\
& \gamma_{s l} \text { - interfacial energy between the liquid and the solid }
\end{aligned}
$$

To ensure optimal cell adhesion to the material, the test material needs to be slightly hydrophilic. It is thus a material on which the applied liquid, e.g. medium, will form a contact angle of about $65^{\circ}$. [1] In order to obtain a slightly hydrophilic surface, it is therefore necessary to find a match between the surface tension of the liquid and the surface energy of the solid.

At present, porous scaffolds are used in tissue engineering, which can be prepared from both fibre systems and hydrogels, or from a combination of a fibre system and a hydrogel. [4-6] 
Both natural polymers and synthetic polymers are used to prepare fibrous scaffolds. The most widely used natural polymers in tissue engineering include collagen, gelatin, chitosan, alginate, or hyaluronic acid. Synthetic polymers used to prepare scaffolds include polyvinyl alcohol, polylactic acid, polyglycolic acid, or polycaprolactone. [13-16] The last mentioned material, polycaprolactone (PCL), was used in this study to produce fibrous layers. It is a semicrystalline hydrophobic polyester. $[7,8] \mathrm{PCL}$, as a biocompatible and biodegradable polymer, is used in tissue engineering to form skin covers [9], to form bone tissue [10], or, for example, for the production of small-diameter vessels [11].

Hydrogels can be defined as hydrophilic, three-dimensional, physically or chemically crosslinked polymer networks that have the ability to absorb large amounts of water or biological fluids. [12,13] Hydrogels are similar in composition and mechanical properties to extracellular matrix (intercellular mass), so they can serve as a support material for cells during tissue regeneration and allow the diffusion of nutrients, metabolites and growth factors. [14,15] Hydrogels are used in tissue engineering primarily to transport drugs or growth factors, such as grafts of irregularly shaped defects, or to fill pores in a three-dimensional network that can sufficiently stabilize the repair site. [14]

\section{MATERIALS AND METHODS}

\subsection{Materials}

PCL with a molecular weight of Mn 80,000 (Sigma-Aldrich, Germany) was chosen for the preparation of nanofibre layers. Three solvent systems were chosen to dissolve the PCL. The first was composed of chloroform and ethanol (both Sigma-Aldrich, Germany), the second solvent system was composed of chloroform, ethanol and acetic acid (Sigma-Aldrich, Germany) and the third solvent system was composed of acetic acid, formic acid and acetone (all Sigma-Aldrich, Germany). Pork skin gelatin (Sigma-Aldrich, Germany) was chosen for the preparation of hydrogel. Distilled water was chosen as the solvent system.

\subsection{Preparation}

PCL was prepared at a concentration of $8 \mathrm{wt} \%$ in three solvent systems. Chloroform and ethanol were in ratio $8: 2$, chloroform, ethanol and acetic acid were in ratio 8:1:1, and the solvent system of acetic acid, formic acid and acetone was in ratio 1:1:1. Gelatin was prepared at a concentration of $10 \mathrm{wt} \%$ in distilled water. The prepared PCL solutions were spun by direct current (DC) spinning and alternating current (AC) spinning. Nanospider NS 1WS500U was used for DC spinning, and a device consisting of ABB KGUG 36 high-voltage transformer and a Thalheimer-Trafowerke ESS 104 variable autotransformer was used for AC spinning.

\subsection{Surface tension}

The surface tension of the gelatin hydrogel was measured on a PocketDyne (Krüss) by measuring the bubble pressure. The measurement was performed at a temperature of $37^{\circ} \mathrm{C}$.

\subsection{Scanning electron microscopy and analysis}

The PCL nanofibre layers were gilded using Quorum Q150R ES, and images of the layers were obtained using a scanning electron microscope (SEM, Tescan Vega3, Czech Republic) at an accelerated voltage of 20kV.

\subsection{Contact angle and surface energy of the fibre layers}

The surface energy was determined via the measurement of the contact angle using a See System E instrument (Advex Instruments, Czech Republic). The liquid used for the measurement of the contact angle comprised glycerol with a surface tension of $64 \mathrm{mN} / \mathrm{m}$. The Kwok-Neumann and Li-Neumann model was used to calculate the surface energy. 


\section{RESULTS AND DISCUSSION}

\subsection{Preparation and spinning of the solutions}

The prepared polymer solutions were spun via the DC spinning at an electrode voltage of $50 \mathrm{kV}$ and a collector voltage of $-10 \mathrm{kV}$. The distance between the collector and the electrode was $170 \mathrm{~mm}$. The polymer solution was also spun via the AC spinning method at an effective voltage of $37 \mathrm{kV}$ and a frequency of $50 \mathrm{~Hz}$. Diagrams of the used devices are shown in Figure 1.
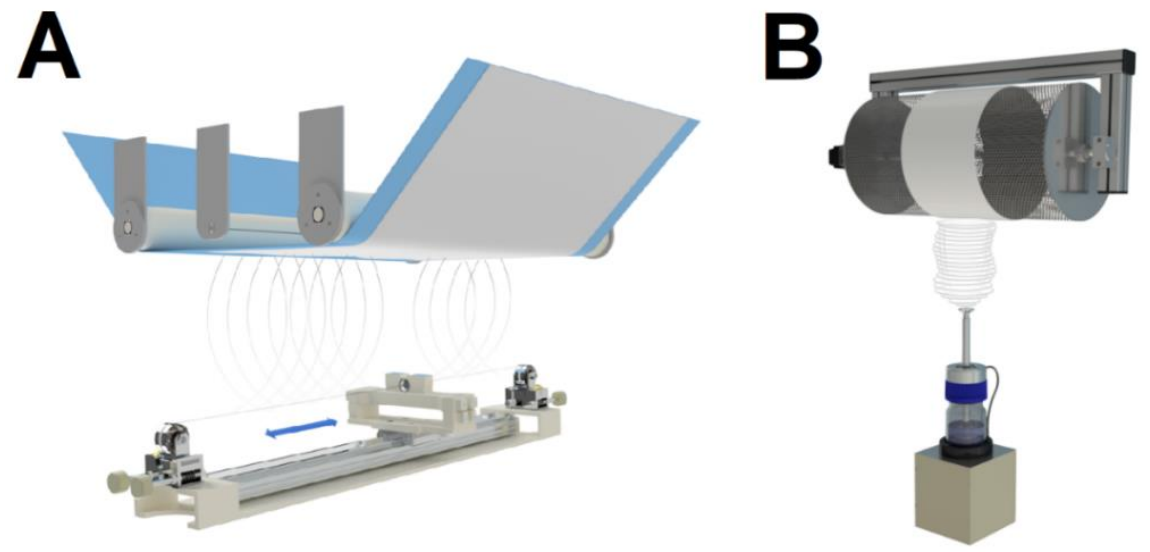

Figure 1 Diagram of the spinning devices. A) the Nanospider spinning device, B) the AC spinning device

\subsection{Fibre morphology and diameter analysis}

During spinning, homogeneous fibrous layers with occasional bead defects were produced. Figure 2 shows SEM images and fibre diameter of the various fibre layers produced via DC spinning and AC spinning.
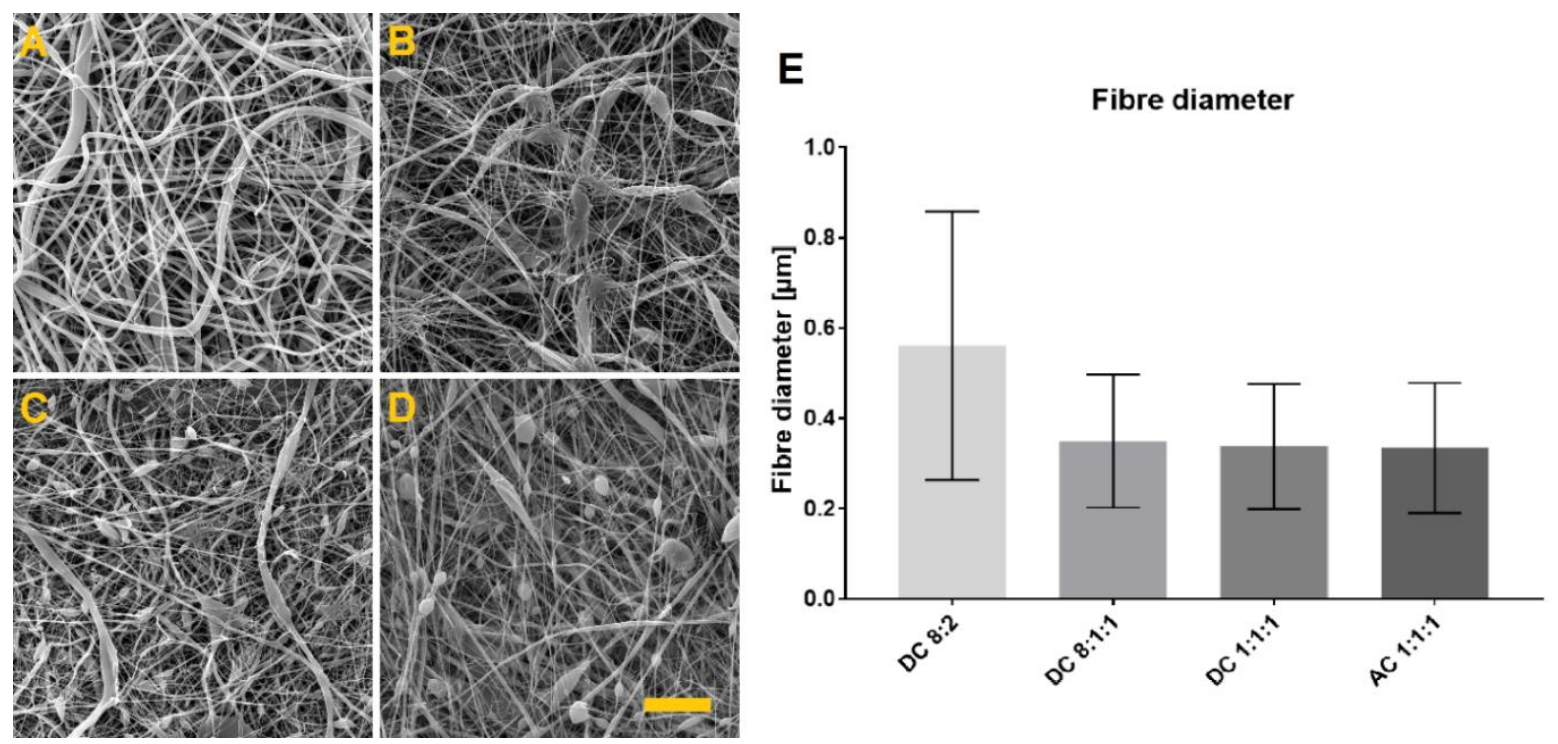

Figure 2 SEM images of the fibre layers. A) DC 8:2, B) DC 8:1:1. C) DC 1:1:1, D) AC 1:1:1, and E) diameter of the produced fibre layers. $95 \%$ confidence interval. ${ }^{* * *} p<0.0001$

\subsection{Surface tension}

The surface tension of the prepared gelatin hydrogel was measured at $37^{\circ} \mathrm{C}$ due to the possible combination with the cell suspension. The measured surface tension was $65.62 \mathrm{mN} / \mathrm{m}$. 


\subsection{Contact angle and surface energy of the fibre layers}

The surface energy was determined by measuring the contact angle with glycerol. The models for calculating surface energy were Kwok-Neumann (2) and Li-Neumann (3). The contact angle and surface energy values are shown in Figure 3.

$$
\begin{aligned}
& \gamma_{s l}=\gamma_{l v}+\gamma_{s v}-2 \sqrt{\gamma_{l v} \gamma_{s v}}\left(1-0.0001057\left(\gamma_{l v-} \gamma_{s v}\right)^{2}\right) \\
& \gamma_{s l}=\gamma_{l v}+\gamma_{s v}-2 \sqrt{\gamma_{l v} \gamma_{s v}} e^{-0.0001247\left(\gamma_{l v}-\gamma_{s v}\right)^{2}}
\end{aligned}
$$
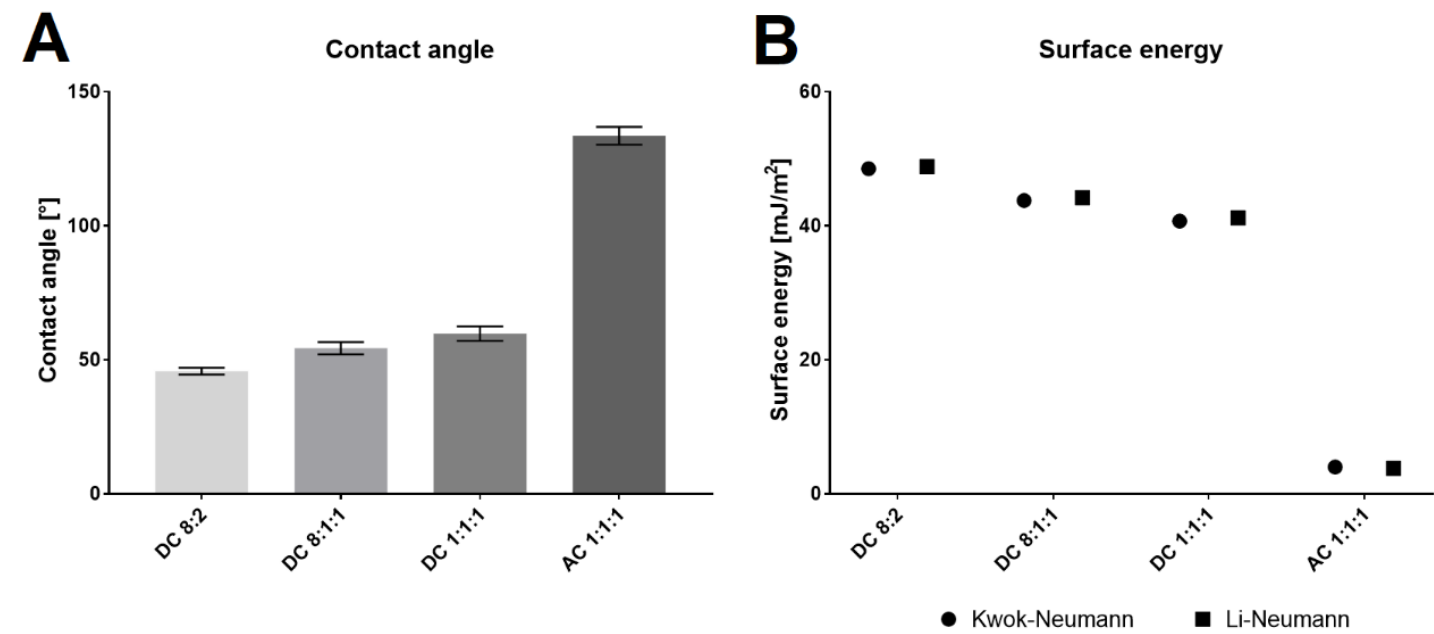

Figure 3 Values of the A) contact angle, and B) surface energy of the fibre layers

\subsection{Theoretical contact angle}

The theoretical contact angle that the gelatin hydrogel will form on the fibrous layers was calculated from the values of the surface energies of the individual fibrous layers and the surface tension of the prepared hydrogel.

By combining the Kwok-Neumann (2) and Li-Neumann (3) relationship with Young's equation (1), we obtain the relations for the calculation of contact angles by the Kwok-Neumann (4) and Li-Neumann model (5).

$$
\begin{aligned}
& \cos \alpha=-1+2 \sqrt{\frac{\gamma_{s v}}{\gamma_{l v}}}\left(1-0.0001057\left(\gamma_{l v}-\gamma_{s v}\right)^{2}\right) \\
& \cos \alpha=-1+2 \sqrt{\frac{\gamma_{s v}}{\gamma_{l v}}} e^{-0.0001247\left(\gamma_{l v}-\gamma_{s v}\right)^{2}}
\end{aligned}
$$

Table 1 shows the values of the theoretical contact angles obtained by the Kwok-Neumann and Li-Neumann methods.

Table 1 Calculated values of theoretical contact angles using Kwok-Neumann and Li-Neumann methods

\begin{tabular}{|c|c|c|c|}
\hline \multirow{2}{*}{ Spinning technology } & \multirow{2}{*}{ Solvent system } & \multicolumn{2}{|c|}{ Theoretical contact angle [ $^{\circ}$ ] } \\
\cline { 3 - 4 } & & Kwok-Neumann & Li-Neumann \\
\hline \multirow{2}{*}{ DC Spinning } & $8: 2$ & 48.2 & 48.2 \\
\hline \multirow{2}{*}{ AC Spinning } & $8: 1: 1$ & 56.6 & 56.6 \\
\hline
\end{tabular}




\subsection{Verification of the theoretical contact angles}

To compare the theoretical contact angles, the real contact angle was measured using a prepared gelatin hydrogel. The measured values of contact angles are given in Table 2. Figure 4 is a graphical comparison of theoretical and real contact angles.

Table 2 Measured values of contact angles

\begin{tabular}{|c|c|c|}
\hline Spinning technology & Solvent system & Contact angle [ $\left.{ }^{\circ}\right]$ \\
\hline \multirow{2}{*}{ DC Spinning } & $8: 2$ & $42.1 \pm 2.2$ \\
\hline \multirow{2}{*}{ AC Spinning } & $8: 1: 1$ & $49.1 \pm 2.1$ \\
\hline
\end{tabular}

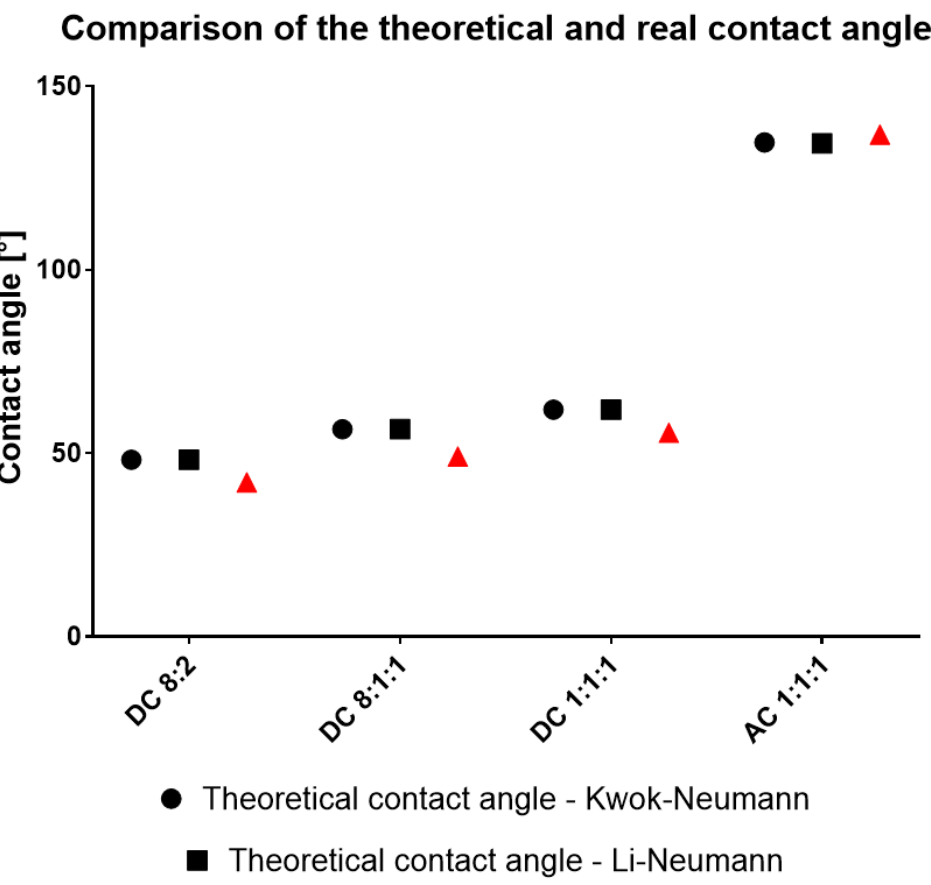

\section{\ Real contact angle}

Figure 4 Comparison of theoretical and real contact angles

From the obtained values it is clear that the theoretical contact angles are close to the actually measured ones. Both models used are therefore suitable for predicting whether a given material will be wetted and what contact angle the selected liquid will make. Figure 5 then captures images of wetting the fibrous layers with a gelatin hydrogel.
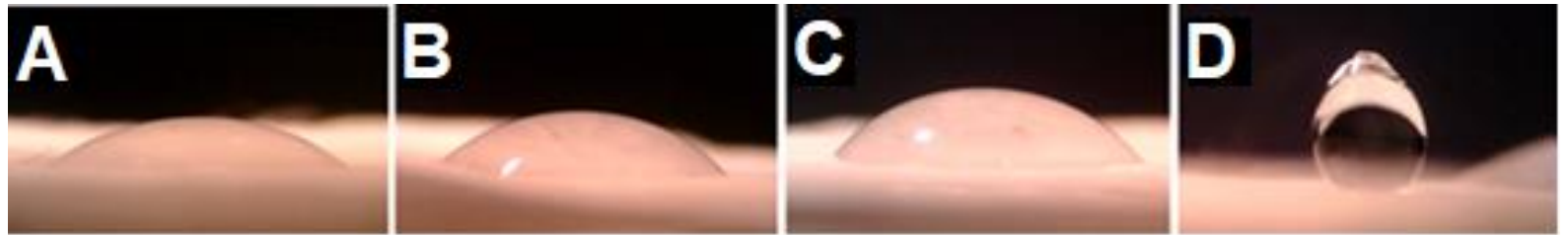

Figure 5 Wetting of the fibrous layers with a gelatin hydrogel. DC spinning layers A) 8:2, B) 8:1:1, C) 1:1:1.

D) Fibre layer from AC spinning 1:1:1 


\section{CONCLUSION}

The study described the wetting of nanofibre layers depending on their surface energy and surface tension of the prepared gelatin hydrogel. In the study, fibre layers were prepared by DC spinning and AC spinning. During the experiments, significant differences in wetting were found between the individual fibre layers. The DC spinning layers produced by the string electrode have high surface energy and are therefore hydrophilic. The fibre layers from the AC spinning have a low surface energy value and are therefore hydrophobic. As part of the study of wetting of the fibrous layers, calculations of the theoretical contact angles that the gelatin hydrogel will form on the fibrous layers were performed. The calculation was performed using the values of surface energies of fibre layers and surface tension of the prepared hydrogel. The resulting real values of the contact angle differ slightly from the theoretical ones, but both models are sufficient for the basic idea of wetting the produced materials.

\section{ACKNOWLEDGEMENTS}

This study was supported by the research of nanofibrous materials for the treatment of glaucoma disease (reg. no. TUL: PURE-2021-6005).

\section{REFERENCES}

[1] DOWLING, D.P.; MILLER, I.S.; ARDHAOUI, M.; GALLAGHER, W.M. Effect of Surface Wettability and Topography on the Adhesion of Osteosarcoma Cells on Plasma-Modified Polystyrene. J Biomater Appl. [online]. 2011, vol. 26, pp. 327-347. Available from: https://doi.org/10.1177/0885328210372148.

[2] MAO, N. 6 - Methods for characterisation of nonwoven structure, property, and performance. In Advances in Technical Nonwovens. KELLIE, G., Ed. Woodhead Publishing Series in Textiles; Woodhead Publishing, 2016, pp. 155-211. ISBN 978-0-08-100575-0.

[3] HEBBAR, R.S.; ISLOOR, A.M.; ISMAIL, A.F. Chapter 12 - Contact Angle Measurements. In Membrane Characterization; HILAL, N., ISMAIL, A.F., MATSUURA, T., OATLEY-RADCLIFFE, D., Eds. Elsevier, 2017; pp. 219-255 ISBN 978-0-444-63776-5.

[4] DHANDAYUTHAPANI, B.; YOSHIDA, Y.; MAEKAWA, T.; KUMAR, D.S. Polymeric Scaffolds in Tissue Engineering Application: A Review. [online]. Available from: https://www.hindawi.com/journals/ijps/2011/290602/ [accessed on 2 September 2020].

[5] PINA, S.; RIBEIRO, V.P.; MARQUES, C.F.; MAIA, F.R.; SILVA, T.H.; REIS, R.L.; OLIVEIRA, J.M. Scaffolding Strategies for Tissue Engineering and Regenerative Medicine Applications. Materials (Basel). [online]. 2019, vol. 12. Available from: $\mathrm{https}: / /$ doi.org/10.3390/ma12111824.

[6] MOHABATPOUR, F.; KARKHANEH, A.; SHARIFI, A.M. A Hydrogel/Fiber Composite Scaffold for Chondrocyte Encapsulation in Cartilage Tissue Regeneration. RSC Adv. [online]. 2016, vol. 6, pp. 83135-83145. Available from: https://doi.org/10.1039/C6RA15592H.

[7] MCKEEN, L. 12 - Renewable Resource and Biodegradable Polymers. In The Effect of Sterilization on Plastics and Elastomers (Third Edition); MCKEEN, L., Ed. Plastics Design Library; William Andrew Publishing: Boston, 2012, pp. 305-317. ISBN 978-1-4557-2598-4.

[8] SAAD, B.; SUTER, U.W. Biodegradable Polymeric Materials. In Encyclopedia of Materials: Science and Technology. BUSCHOW, K.H.J., CAHN, R.W., FLEMINGS, M.C., ILSCHNER, B., KRAMER, E.J., MAHAJAN, S., VEYSSIĖRE, P., Eds. Elsevier: Oxford, 2001; pp. 551-555. ISBN 978-0-08-043152-9.

[9] KLICOVA, M.; KLAPSTOVA, A.; CHVOJKA, J.; KOPRIVOVA, B.; JENCOVA, V.; HORAKOVA, J. Novel DoubleLayered Planar Scaffold Combining Electrospun PCL Fibers and PVA Hydrogels with High Shape Integrity and Water Stability. Materials Letters. [online]. 2020, vol. 263, p. 127281. Available from: https://doi.org/10.1016/j.matlet.2019.127281.

[10] RAMPICHOVÁ, M.; CHVOJKA, J.; JENČOVÁ, V.; KUBÍKOVÁ, T.; TONAR, Z.; ERBEN, J.; BUZGO, M.; DAŇKOVÁ, J.; LITVINEC, A.; VOCETKOVÁ, K.; et al. The Combination of Nanofibrous and Microfibrous Materials for Enhancement of Cell Infiltration and in Vivo Bone Tissue Formation. Biomed Mater. [online]. 2018, vol. 13, p. 025004. Available from: https://doi.org/10.1088/1748-605X/aa9717. 
[11] YALCIN, I.; HORAKOVA, J.; MIKES, P.; SADIKOGLU, T.G.; DOMIN, R.; LUKAS, D. Design of Polycaprolactone Vascular Grafts. Journal of Industrial Textiles. [online]. 2016, vol. 45, pp. 813-833, Available from: https://doi.org/10.1177/1528083714540701.

[12] BATISTA, R.A.; OTONI, C.G.; ESPITIA, P.J.P. Chapter 3 - Fundamentals of chitosan-based hydrogels: elaboration and characterization techniques. In Materials for Biomedical Engineering; HOLBAN, A.-M., GRUMEZESCU, A.M., Eds. Elsevier, 2019, pp. 61-81. ISBN 978-0-12-816901-8.

[13] AHMED, E.M. Hydrogel: Preparation, Characterization, and Applications: A Review. Journal of Advanced Research. [online]. 2015, vol. 6, pp. 105-121. Available from: https://doi.org/10.1016/j.jare.2013.07.006.

[14] HESSE, E., HEFFERAN, T.E., TARARA, J.E., HAASPER, C., MELLER, R., KRETTEK, C., LU, L., YASZEMSKI, M.J. Collagen Type I Hydrogel Allows Migration, Proliferation and Osteogenic Differentiation of Rat Bone Marrow Stromal Cells. J Biomed Mater Res A. [online]. 2010, vol. 94, pp. 442-449. Available from: https://doi.org/10.1002/jbm.a.32696.

[15] KOETTING, M.C., PETERS, J.T., STEICHEN, S.D., PEPPAS, N.A. Stimulus-Responsive Hydrogels: Theory, Modern Advances, and Applications. Materials Science and Engineering: R: Reports. [online]. 2015, vol. 93, pp. 1-49. Available from: https://doi.org/10.1016/j.mser.2015.04.001. 